\title{
Men's preferences for prostate cancer screening: a discrete choice experiment
}

\author{
E W de Bekker-Grob*,1 J M Rose ${ }^{2}$, B Donkers ${ }^{3}$, M-L Essink-Bot ${ }^{4}$, C H Bangma ${ }^{5}$ and E W Steyerberg ${ }^{1}$ \\ ${ }^{1}$ Department of Public Health, Erasmus MC-University Medical Centre Rotterdam, PO Box 2040, 3000 CA Rotterdam, The \\ Netherlands; ${ }^{2}$ Institute of Transport and Logistics Studies, University of Sydney, Sydney, New South Wales, Australia; ${ }^{3}$ Department \\ of Business Economics, Erasmus University, Rotterdam, The Netherlands; ${ }^{4}$ Department of Social Medicine, Academic MC, \\ University of Amsterdam, Amsterdam, The Netherlands and ${ }^{5}$ Department of Urology, Erasmus MC_University Medical Centre \\ Rotterdam, Rotterdam, The Netherlands
}

Background: Screening for prostate cancer (PC) may save lives, but overdiagnosis and overtreatment are serious drawbacks. We aimed to determine men's preferences for PC screening, and to elicit the trade-offs they make.

Methods: A discrete choice experiment (DCE) was conducted among a population-based random sample of 1000 elderly men (55-75-years-old). Trade-offs were quantified with a panel latent class model between five PC screening aspects: risk reduction of PC-related death, screening interval, risk of unnecessary biopsies, risk of unnecessary treatments, and out-of-pocket costs.

Results: The response rate was $46 \%$ (459/1000). Men were willing to trade-off $2.0 \%$ (Cl: $1.6 \%-2.4 \%$ ) or $1.8 \%$ (Cl: 1.3\%-2.3\%) risk reduction of PC-related death to decrease their risk of unnecessary treatment or biopsy with $10 \%$, respectively. They were willing to pay $€ 188$ per year ( $\mathrm{Cl}: € 141-€ 258$ ) to reduce their relative risk of $\mathrm{PC}$-related death with $10 \%$. Preference heterogeneity was substantial, with men with higher educational levels having a lower probability to opt for PC screening than men with lower educational levels.

Conclusion: Men were willing to trade-off some risk reduction of PC-related death to be relieved of the burden of biopsies or unnecessary treatments. Increasing knowledge on overdiagnosis and overtreatment, especially for men with lower educational levels, is warranted to prevent unrealistic expectations from PC screening.

Prostate cancer (PC) is a major health issue. Screening for PC based on the prostate-specific antigen (PSA) test has potential to save lives, but three out of every four men who undergo a biopsy have a negative biopsy, as the PSA test lacks specificity (Schroder et al, 2009). Additionally, the PSA test is poor at discriminating between men with clinically significant cancer $v s$ those who have little to gain (Roobol et al, 2009). The PSA test may detect small cancers that would never surface clinically during lifetime. This overdiagnosis puts men at risk of treatment complications.

Current PSA screening is hence unattractive due to overdiagnosis and overtreatment. However, the decision to participate or not in any screening programme is preferably based on an individual decision-making process of weighting the test burden against the potential benefits of screening. A man will make trade- offs between what he perceives as the expected advantages and disadvantages, e.g., how negative it would be if he were to suffer from permanent erectile dysfunction due to PC screening.

Patients' preferences can have a major impact on their willingness to use health care services (Phillips et al, 2006). To improve patient-centred health care it is important to investigate men's preferences for PC screening. Additionally, obtaining insight into these preferences is relevant to inform clinicians and policy decision makers, and for planning screening programmes. However, quantitative studies investigating men's preferences for PC screening are lacking. We investigated the preferences of men aged 55-75 years for PC screening. We hereto used a discrete choice experiment (DCE), a quantitative approach that is increasingly used in health care (Ryan and Gerard, 2003; de Bekker-Grob et al, 2012). 


\section{MATERIALS AND METHODS}

Discrete choice experiment. In a DCE it is assumed that a medical intervention, such as a screening programme, can be described by its characteristics (attributes; e.g., screening interval) (Ryan, 2004). Those characteristics are further specified by variants of that characteristic (attribute levels; e.g., for screening interval: every 2, 3, and 4 years). A second assumption is that the individual's preference for a medical intervention is determined by the levels of those attributes (Ryan, 2004). The relative importance of attributes and the trade-offs that respondents make between them can be assessed by offering a series of choices between two or more medical intervention alternatives with different combinations of attribute levels (Hensher et al, 2005) (Appendix 1). In comparison with other stated preference techniques, a DCE presents a reasonably straightforward task and one which more closely resembles a real-world decision (Mangham et al, 2009).

Attributes and levels. We used literature (Draisma et al, 2003; Sennfalt et al, 2006; Andriole et al, 2009; Schroder et al, 2009; Hugosson et al, 2010), interviews with experts in the field of PC screening $(n=8)$ and men aged $55-75$ years $(n=8$; i.e., the target group) to obtain insights into PC screening attributes and their levels. We asked experts and men in the interviews to comment on and complete the list of PC screening attributes that was created from literature review. We also asked men to rank the attributes from most important to less important with respect to their preferences for PC screening. The number of attributes in a DCE is limited (because of impact on the random component variability), and the ranking results allowed us to make an a priori selection of the five most relevant attributes: risk reduction of PC-related death, screening interval, risk of unnecessary biopsies, risk of unnecessary treatments, and out-of-pocket costs (Table 1). Unnecessary biopsies and treatments are defined as unnecessary at the aggregate level.

Study design and questionnaire. The combination of five attributes with four levels each would result in $1024\left(4^{5}\right)$ potential PC screening alternatives. As it is not feasible to present a single individual with all these alternatives, we generated a sample from all these 1024 alternatives. We used an efficient design by maximising D-efficiency (SAS software version 9.1, SAS Institute Inc., Cary, NC, USA) (Street et al, 2005). Thirty-two choice sets were constructed. As the cognitive burden may increase with the number of choice sets beyond a certain threshold, the 32 choice sets were blocked (Hensher et al, 2005) into two versions of questionnaires containing 16 choice sets each (Bech et al, 2011). Choice sets consisted of two PC screening alternatives and a 'no PC screening' option to allow respondents to 'opt out' (Appendix 1). The 'opt out' alternative was necessary as PC screening is a preventive intervention and, as in real life, respondents are not obliged to undertake PC screening. Respondents were asked to consider all three alternatives in a choice set as realistic alternatives and to choose the alternative that appealed most to them. The questionnaire further contained questions on background variables (e.g., age, educational level, generic health status) and a question assessing experienced difficulty of the questionnaire (five-point scale) (the complete questionnaire is available from the authors on request). We conducted a pilot study $(n=10)$ to ascertain respondents could manage the length of the questionnaire and to examine the intelligibility, acceptability, and validity of the questionnaire. As none of the respondents raised any problems, no alterations were made.

Study sample. A representative sample of 1000 men aged 55-75 years was randomly recruited using the population registry of the region Rijnmond in the Southwest of the Netherlands. Calculation

\begin{tabular}{|c|c|}
\hline Attributes ${ }^{a}$ & Levels \\
\hline $\begin{array}{l}\text { Risk reduction of death from prostate } \\
\text { cancer }\end{array}$ & $\begin{array}{l}3.5 \% \rightarrow 3.2 \% \text { (10\% relative risk } \\
\text { reduction) } \\
3.5 \% \rightarrow 2.8 \% \text { (20\% relative risk } \\
\text { reduction) } \\
3.5 \% \rightarrow 2.5 \% \text { (30\% relative risk } \\
\text { reduction) } \\
3.5 \% \rightarrow 1.8 \% \text { (50\% relative risk } \\
\text { reduction) }\end{array}$ \\
\hline Screening interval & $\begin{array}{l}\text { Every year } \\
\text { Every } 2 \text { years } \\
\text { Every } 3 \text { years } \\
\text { Every } 4 \text { years (reference level) }\end{array}$ \\
\hline Risk of unnecessary biopsy & $\begin{array}{l}20 \% \\
40 \% \\
60 \% \\
80 \% \\
\end{array}$ \\
\hline Risk of unnecessary treatment & \begin{tabular}{|l|}
$0 \%$ \\
$20 \%$ \\
$50 \%$ \\
$80 \%$ \\
\end{tabular} \\
\hline Out-of-pocket costs & $\begin{array}{l}€ 0 \\
€ 50 \\
€ 100 \\
€ 300\end{array}$ \\
\hline
\end{tabular}

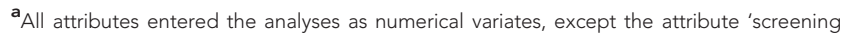
interval'. This latter attribute was entered the analyses as a categorical variate with 'every 4 years' as reference level.

of optimal sample sizes is complicated as it depends on the true values of the unknown parameters estimated in the discrete choice models (Lancsar and Louviere, 2008). Earlier studies have shown that sample sizes of 300-400 respondents are sufficient for reliable statistical analyses (Bishop et al, 2004; Herbild et al, 2009; de Bekker-Grob et al, 2010a). Therefore, taking into account an expected response rate of $40 \%$ (Wordsworth et al, 2006; de BekkerGrob et al, 2010b), we recruited a representative sample of $n=1000$. We checked a posterior whether our sample size was sufficient to find significant differences for each attribute(level) at a $5 \%$ level using the true values of the estimated parameters and NGene software (http://www.choice-metrics.com/).

Invitation of subjects. Subjects were contacted by mail. They received a questionnaire and an information brochure about PC and PC screening. Individuals could return the questionnaire in a postage-paid envelope that was included in the mailing package. A reminder was sent 4 weeks later in case of non-response. Approval for the study was obtained from the Medical Ethics Committee, Erasmus MC (MEC-2010-316).

Statistical analyses. Several models exist to analyse discrete choice data (see De Bekker-Grob et al. (2012) for an overview). Taking our interest in preference heterogeneity into account, as well as our sample size, a mixed logit model or a latent class model were both good alternatives to analyse the choice observations. Although, the best mixed logit model had a somewhat better model fit for the choice observations than the best latent class model (pseudo- $R^{2}=0.42$ vs 0.41 using NLogit software (http://www.limdep.com/)), we preferred to use a latent class model due to its advantages (Swait, 1994). A latent class model can be used to identify the existence and the number of segments or classes, $C$, in the population (i.e., identifying different utility (preference) 
functions across unobserved subgroups). Class membership is latent in that each respondent belongs to each class up to a modelled probability and not deterministically assigned by the analyst $a$ priori. The model is flexible in that the probability that sampled respondents belong to a particular class can be linked to covariates (e.g., age, income), hence allowing for some understanding as to the make-up of the various class segments (see Appendix 2 for more details). This additional information can be really useful for physicians, and counterbalance the somewhat lower model fit compared with the best mixed logit model. Further, outside of the health care literature, there is growing anxiety as to the appropriate use of outputs from the mixed logit model (Daly et al, 2012). The use of the latent class model, overcomes this issue, while still allowing for all of the advantages of the mixed logit model.

We used a panel latent class model. A panel latent class model accounts for the panel nature of the data as each respondent completed 16 choice tasks. In order to determine the number of classes, we selected the model with the best fit based on the AIC criterion. We tested a number of different specifications for the utility function (e.g., categorical or numerical attribute levels, twoway interactions between attributes, several attribute transformations). The optimal utility function was:

$$
\begin{aligned}
& V_{n s j \mid c}=\beta_{0 \mid c}+\beta_{1 \mid c} \text { reduction of deaths } s_{n s j \mid c}+\beta_{2 \mid c} \text { interval }(1 \mathrm{yr})_{n s j \mid c} \\
& +\beta_{3 \mid c} \text { interval }(2 \mathrm{yrs})_{n s j \mid c}+\beta_{4 \mid c} \text { interval }(3 \mathrm{yrs})_{n s j \mid c}+\beta_{5 \mid c} \text { biopsy }_{n s j \mid c} \\
& +\beta_{6 \mid c} \text { treatment }_{n s j \mid c}+\beta_{7 \mid c} \operatorname{costs}_{n s j \mid c}+\beta_{8 \mid c} \text { reduction of deaths } s_{n s j \mid c} \\
& \times \operatorname{costs}_{n s j \mid c}+\beta_{9 \mid c} \text { biopsy }_{n s j \mid c} \times \operatorname{costs}_{n s j \mid c}+\beta_{10 \mid c} \text { treatment }_{n s j \mid c} \\
& \times \operatorname{costs}_{n s j \mid c}+\beta_{11 \mid c} \text { reduction of deaths } s_{n s j \mid c} \times \text { biopsy }_{n s j \mid c} \\
& +\beta_{12 \mid c} \operatorname{costs}_{n s j \mid c}^{2}+\beta_{13 \mid c} \text { reduction of deaths }{ }_{n s j \mid c}^{2}
\end{aligned}
$$

where

$V_{n s j c}$ represent the observable utility that respondent $n$ belonging to class segment $c$ has for alternative $j$ in choice set $s$;

$\beta_{0 \mid c} \quad$ represents an alternative-specific constant for a certain class;

$\beta_{1-7 \mid c}$ are class-specific parameter weights (coefficients) linearly associated with each attribute of the DCE;

$\beta_{8-11 \mid c}$ are class-specific two-way interaction effects (i.e., an effect where the influence of one attribute depends on the level of another attribute); and

$\beta_{12-13 \mid c}$ are class-specific parameter weights associated with attribute transformations.

In addition to the utility function, the final model allowed for several covariates (education, depressed/anxious feelings, and stated willingness to pay (WTP) for PC screening) to enter into the class assignment model (Appendix 2). The class assignment utility function for the final model was (see Equation (2)):

$$
\begin{aligned}
& V_{n c}=\beta_{0 c}+\beta_{1 c} \text { higher education } \\
& +\beta_{2 c} \text { depression }_{n}+\beta_{3 c} \operatorname{wtp}(100 \text { euros })_{n}
\end{aligned}
$$

For the class coefficients, the statistical significance of a coefficient $(P$-value $\leqslant 0.05)$ indicates that conditional to belonging to that class, respondents considered the attribute important in making their choices in the DCE. The sign of the coefficient reflects whether the attribute has a positive or negative effect on utility. We expected that only the attribute 'risk reduction of PC-related death' and one or more levels of 'screening interval' would have a positive effect (i.e., a positive sign) (Hol et al, 2010; van Dam et al, 2010). In terms of the class assignment parameters, statistically significant parameter estimates indicate that the associate covariate can be used to help in understanding the different segments. For example, if the depression parameter associated with a particular class in the assignment model is positive and significant, then this is indicative that people who suffer depression are more likely to belong to that particular class as given in Equation (1).

Trade-offs. We calculated the WTP values for each of the attributes. A WTP value represents how much one is willing to pay for a one unit change in the attribute of interest, and is calculated by taking the ratio of the parameter for attribute $k$ to the parameter related to cost. For the latent class model however, several potential WTP measures can be derived. Firstly, it is possible to calculate the conditional class WTP values. In the model, each class will have a set of parameter estimates associated with Equation (1). As such, conditional to belonging to class $c$, the conditional WTP can be computed as

$$
W T P_{k \mid c}=\frac{\beta_{k \mid c}}{\beta_{7 \mid c}} .
$$

While of theoretical interest, the WTP measures derived from Equation (3) are likely to be of limited relevance to the analyst. This is because the model assumes that respondents belong to all classes up to a probability (and not to just one class). It is possible however to obtain overall WTP measures by weighting the conditional WTP values by the probability that respondents belongs to a given class (given by the class assignment probability in Equation (1)). That is (see Equation (4)):

$$
\mathrm{WTP}_{\mathrm{k}}=\sum_{c}^{c} P_{c} \frac{\beta_{k \mid c}}{\beta_{7 \mid c}}
$$

In the current paper, we compute the latter marginal WTP values. We also compute the confidence intervals based on the individual-specific WTP estimates using the Krinsky and Robb procedure (Krinsky and Robb, 1986).

\section{RESULTS}

Respondents. The response rate to the questionnaire was 459/ 1000 (46\%, Figure 1). Respondents did not differ from nonrespondents in age $(P=0.62)$ or marital status $(0.44)$. Of the 459 respondents, 427 (93\%) completed the DCE task. These respondents had a mean age of 63.3 years $($ s.d. $=5.2)$, one-third had a

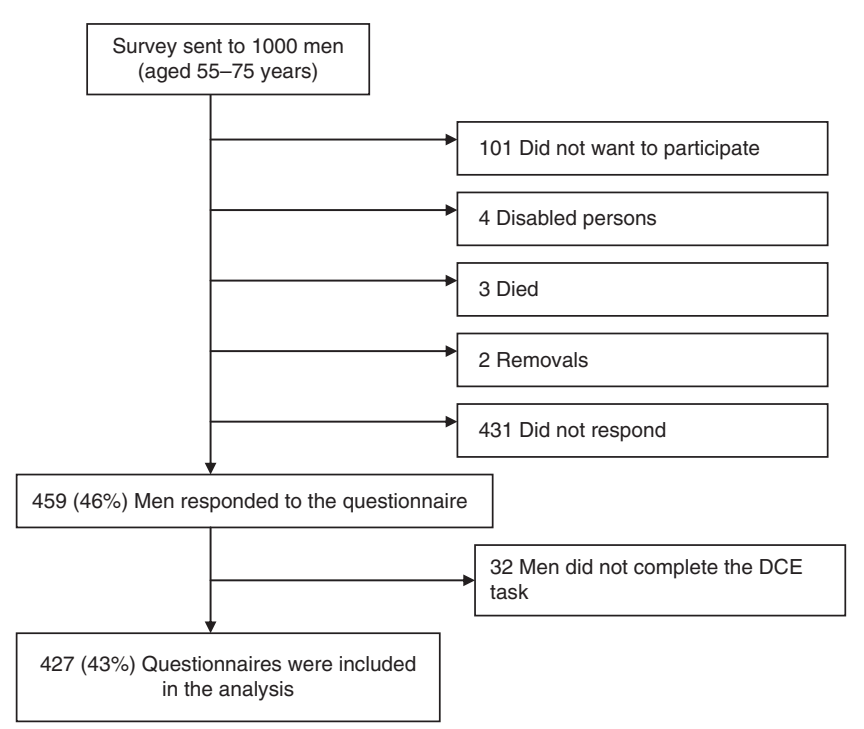

Figure 1. Overview of subjects accessing the study. 




higher educational level, and they lived predominantly together with a partner. Three per cent had been treated for PC (Table 2).

Discrete choice experiment results. Three classes were identified (Table 3). The average class probabilities within the sampled population were $60.8 \%, 23.0 \%$, and $16.2 \%$ for latent class 1,2 , and 3 respectively. However, the probability to belong to a specific class depended on the educational level of the respondent, whether he had anxiety/depression feelings, and his stated WTP for receiving a PC screening programme (not to be confused with the derived WTP value obtained from the model; see Equation (3)). To be more precise, respondents who had a higher educational level, had a higher probability to belong to latent class 3; respondents, who were willing to pay for PC screening had a higher probability to belong to latent class 1; whereas respondents who had anxiety/ depression feeling had a higher probability to belong to latent class 3. Hence, taking all these patient characteristics into account, respondents, who had a lower educational level, did not have anxiety/depression feelings, and were willing to pay for PC screening, had a higher probability to belong to latent class 1 $(68.1 \%, 21.4 \%$, and $10.5 \%$ for latent class 1,2 , and 3 respectively).
However, if respondents had a lower educational level, had anxiety/ depression feelings and were not willing to pay for PC screening, the probability to belong to latent class 2 was the highest $(28.3 \%$, $40.1 \%$, and $31.6 \%$ for latent classes 1,2 , and 3, respectively). Respondents with a higher educational level, who had anxiety or depression feelings, and were not willing to pay for PC screening, had the highest probability to belong to latent class $3(20.8 \%$, $30.7 \%$, and $48.6 \%$ for latent class 1,2 , and 3 respectively).

The estimated coefficients for each latent class had the expected sign and were significant in most cases (Table 3) and showed, therefore, theoretical validity. The positive sign given to the coefficient 'risk reduction of PC-related death' indicated that men preferred a PC screening programme generating a higher reduction of PC-related death over a PC screening programme that generates a lower reduction of PC-related death. The negative signs for 'risk of unnecessary treatment and biopsy' and 'out-of-pocket costs' indicate that men preferred a PC screening programme with a low risk of unnecessary treatment and biopsy, and low out-of-pocket costs.

All five PC screening aspects significantly influenced men's preferences, although the preference heterogeneity was substantial. Nevertheless, irrespective of the latent class respondents belong to, risk reduction of PC death, risk of unnecessary treatment and biopsy, as well as costs, they were all important for respondents' preferences, whereas screening interval was not. Respondents who belong to latent class 1 showed a strong preference for a shorter screening interval. Although respondents who belong to latent class 3 also showed a preference for screening every 2 years over screening every 4 years, such respondents significantly preferred screening every 4 years over screening every year. In contrary, for latent class 2 the screening interval did not have an influence on preferences for PC screening at all.

Assuming a realistic PC screening programme (i.e., 20\% risk reduction of PC-related death, screening interval every 4 years, $60 \%$ risk of an unnecessary biopsy, $50 \%$ risk of an unnecessary treatment, and no out-of-pocket costs) the utilities were 2.7, 4.6, and -0.6 based on latent class 1,2 , and 3 respectively (see Equation (1) and Table 3). That is, respondents belonging to latent class 1 or 2 preferred this realistic PC screening scenario over no screening $(V=2.7>V=0 ;$ and $V=4.6>V=0$ respectively). However, respondents belonging to latent class 3 did not prefer this PC screening programme over no screening $(V=-0.6$ $<V=0$ ). More general, assuming realistic attribute levels of PC screening, men with a lower educational level had a higher probability to prefer PC screening over no PC screening compared with men with a higher educational level, all else being equal. The same conclusion can be made for men who were willing to pay for PC screening or for men without anxiety/depressed feelings. That is, men who were willing to pay for PC screening and/or did not have anxiety/depressed feelings, had a higher probability to prefer PC screening over no PC screening compared with men who were not willing to pay for PC screening and/or had anxiety/depressed feelings, all else being equal.

\section{Trade-offs}

Willingness to pay. Based on the expressed preferences, men were willing to pay $€ 188$ per year (CI: $€ 141-€ 258)$ to reduce their relative risk of PC-related death with $10 \%$ (Table 4). They were willing to pay $€ 33$ per year (CI: $€ 23-€ 48)$ to decrease their risk of unnecessary biopsy with $10 \%$, $€ 38$ per year (CI: $€ 27-€ 53)$ to decrease their risk of unnecessary treatment with $10 \%$, or $€ 87$ per year (CI: $€ 48-€ 137)$ to get a PC screening programme with a screening interval of every 2 years instead of every 4 years. The wide range of CIs showed that the difference in WTP was considerable, which proved the existence of preference heterogeneity. 
Table 3. Men's preferences for prostate cancer screening based on a panel latent class logit model with three latent classes

\begin{tabular}{|c|c|c|c|c|c|c|}
\hline \multirow[b]{2}{*}{ Attribute } & \multicolumn{2}{|c|}{ Latent class 1} & \multicolumn{2}{|c|}{ Latent class 2} & \multicolumn{2}{|c|}{ Latent class 3} \\
\hline & Coefficient & t-ratio & Coefficient & t-ratio & Coefficient & $t$-ratio \\
\hline $\begin{array}{l}\text { Constant } \\
\text { Risk reduction of PC death (per 10\%) }\end{array}$ & $\begin{array}{l}3.16^{\star \star \star} \\
0.93^{\star \star \star}\end{array}$ & $\begin{array}{l}9.71 \\
8.63\end{array}$ & $\begin{array}{l}4.67^{\star \star \star} \\
0.40^{\star \star \star}\end{array}$ & $\begin{array}{c}13.50 \\
2.90\end{array}$ & $\begin{array}{l}-0.65^{\star} \\
0.82^{\star \star \star}\end{array}$ & $\begin{array}{l}-1.90 \\
5.24\end{array}$ \\
\hline $\begin{array}{l}\text { Screening interval } \\
\text { Every year } \\
\text { Every } 2 \text { years } \\
\text { Every } 3 \text { years } \\
\text { Risk unnecessary biopsy (per 10\%) } \\
\text { Risk unnecessary treatment (per 10\%) } \\
\text { Out-of-pocket costs (per } € 100 \text { ) } \\
\text { Risk reduction PC death } \times \text { costs } \\
\text { Biopsy } \times \text { costs } \\
\text { Treatment } \times \text { costs } \\
\text { Risk reduction PC death } \times \text { biopsy } \\
\text { Costs }{ }^{2} \\
\text { Risk reduction PC death }{ }^{2}\end{array}$ & $\begin{array}{c}0.10^{\star \star} \\
0.20^{\star \star \star} \\
-0.02 \\
-0.10^{\star \star} \\
-0.10^{\star \star \star} \\
0.07 \\
0.06^{\star \star \star} \\
0.07^{\star \star \star} \\
-0.01 \\
-0.02^{\star \star} \\
-0.07^{\star \star \star} \\
-0.18^{\star \star \star}\end{array}$ & $\begin{array}{l}1.99 \\
3.97 \\
-0.31 \\
-2.57 \\
-5.30 \\
0.40 \\
2.72 \\
3.37 \\
-0.35 \\
-1.99 \\
-5.16 \\
-5.98\end{array}$ & $\begin{array}{c}-0.05 \\
0.09 \\
-0.02 \\
-0.27^{\star \star \star} \\
-0.04^{\star} \\
-1.32^{\star \star \star} \\
-0.01 \\
0.04 \\
0.05^{\star \star} \\
0.07^{\star \star \star} \\
0.01 \\
0.03\end{array}$ & $\begin{array}{c}-0.77 \\
1.47 \\
-0.24 \\
-6.09 \\
-1.77 \\
-5.40 \\
-0.09 \\
1.61 \\
2.33 \\
5.59 \\
0.28 \\
1.55\end{array}$ & $\begin{array}{c}-0.20^{\star \star} \\
0.21^{\star \star \star} \\
-0.07 \\
-0.03 \\
-0.17^{\star \star \star} \\
-1.10^{\star \star \star} \\
0.02 \\
0.03 \\
0.05^{\star \star \star} \\
-0.03^{\star \star} \\
0.10^{\star \star} \\
-0.06^{\star \star \star}\end{array}$ & $\begin{array}{c}-2.43 \\
2.89 \\
-0.84 \\
-0.70 \\
-8.67 \\
-4.65 \\
0.59 \\
1.12 \\
3.09 \\
-2.29 \\
2.19 \\
-3.33\end{array}$ \\
\hline \multicolumn{7}{|l|}{ Class probability model } \\
\hline $\begin{array}{l}\text { Constant } \\
\text { Higher eduction } \\
\text { Depression } \\
\text { Willingness to pay (per } € 100 \text { ) }\end{array}$ & $\begin{array}{c}1.62^{\star \star \star} \\
-0.74^{\star \star} \\
-1.73^{\star \star \star} \\
0.25^{\star \star}\end{array}$ & $\begin{array}{c}7.03 \\
-2.35 \\
-3.88 \\
2.97\end{array}$ & $\begin{array}{c}0.69^{\star \star \star} \\
-0.70^{\star} \\
-0.45 \\
0.02\end{array}$ & $\begin{array}{c}2.68 \\
-1.86 \\
-1.00 \\
0.29\end{array}$ & $\begin{array}{l}- \\
- \\
- \\
-\end{array}$ & $\begin{array}{l}- \\
- \\
- \\
-\end{array}$ \\
\hline \multicolumn{7}{|l|}{ Class probability } \\
\hline Average & 0.608 & & 0.230 & & 0.162 & \\
\hline \multicolumn{7}{|l|}{ Model fits } \\
\hline $\begin{array}{l}\text { Log-likelihood } \\
\text { AIC } \\
\text { BIC } \\
\text { Pseudo R-squared }\end{array}$ & $\begin{array}{c}-4334.89 \\
1.32 \\
1.37 \\
0.41\end{array}$ & & & & & \\
\hline
\end{tabular}

Table 4. Willingness to pay to achieve an improvement in one of the prostate screening attributes

\begin{tabular}{|l|l|l|}
\hline Attribute & WTP $(€ ; \mathrm{Cl})$ & To receive a screening programme \\
\hline Mortality reduction & $187.6(140.6$ to 257.8$)$ & With $10 \%$ more prostate cancer-related mortality reduction \\
\hline Screening interval & $9.7(-24.9$ to 46.5$)$ & Every year instead of every 4 years \\
\hline & $86.9(48.2$ to 136.8$)$ & Every 2 years instead of every 4 years \\
\hline & $-12.0(-50.2$ to 27.4$)$ & Every 3 years instead of every 4 years \\
\hline Unnecessary treatment & $37.6(26.7$ to 53.0$)$ & With $10 \%$ less risk of unnecessary treatments \\
\hline Unnecessary biopsy & $33.4(22.5$ to 48.4$)$ & With $10 \%$ less risk of unnecessary biopsies \\
\hline $\begin{array}{l}\text { Abbreviations: } \mathrm{Cl}=\text { confidence interval; } \epsilon=\text { euro; } \text { WTP }=\text { willingness to pay. } \mathrm{Cl}=95 \% \text { confidence interval based on the Krinsky Robb method adjusted for class probabilities. The average values } \\
\text { of the interactions are taken into account (i.e., costs }=€ 112.50 ; \text { mortality reduction }=27.5 \% ; \text { unnecessary treatment }=37.5 \% \text {; unnecessary biopsy }=50 \%) .\end{array}$ \\
\hline
\end{tabular}

Willingness to trade of risk reduction of PC-related death. Men were willing to trade-off $2.0 \%$ (CI: $1.6 \%-2.4 \%$ ) risk reduction of PC-related death to decrease their risk of unnecessary treatment with $10 \%, 1.8 \%$ (CI: $1.3 \%$ to $2.3 \%$ ) to decrease their risk of unnecessary biopsy with $10 \%$, or $4.6 \%$ (CI: $2.8 \%$ to $6.4 \%$ ) to get a PC screening programme with an screening interval of every 2 years instead of every 4 years (Table 5). Again, the wide range of $\mathrm{CIs}$ regarding the willingness to trade of risk reduction of PCrelated death proved the existence of preference heterogeneity.

\section{DISCUSSION}

Risk reduction of PC-related death, screening interval, risk of unnecessary biopsies and treatments, and out-of-pocket costs, all influenced men's preferences for PC screening. However, substantial preference heterogeneity existed. Assuming a realistic PC screening programme, men with a lower educational level had a higher probability to opt for PC screening than men with a higher 


\begin{tabular}{|c|c|c|}
\hline \multicolumn{3}{|c|}{$\begin{array}{l}\text { Table } 5 \text {. Willingness to trade mortality risk to achieve an improvement in } \\
\text { one of the prostate screening attributes }\end{array}$} \\
\hline Attribute & $\begin{array}{l}\text { Willingness to trade } \\
\text { mortality risk (\%; Cl) }\end{array}$ & $\begin{array}{l}\text { To receive a } \\
\text { screening programme }\end{array}$ \\
\hline $\begin{array}{l}\text { Unnecessary } \\
\text { treatment }\end{array}$ & 2.0 (1.6 to 2.4$)$ & $\begin{array}{l}\text { With } 10 \% \text { less risk of } \\
\text { unnecessary treatments }\end{array}$ \\
\hline \multirow[t]{3}{*}{$\begin{array}{l}\text { Screening } \\
\text { interval }\end{array}$} & $0.5(-1.3$ to 2.4$)$ & $\begin{array}{l}\text { Every year instead of } \\
\text { every } 4 \text { years }\end{array}$ \\
\hline & $4.6(2.8$ to 6.4$)$ & $\begin{array}{l}\text { Every } 2 \text { years instead of } \\
\text { every } 4 \text { years }\end{array}$ \\
\hline & $-0.7(-2.8$ to 1.4$)$ & $\begin{array}{l}\text { Every } 3 \text { years instead of } \\
\text { every } 4 \text { years }\end{array}$ \\
\hline $\begin{array}{l}\text { Unnecessary } \\
\text { biopsy }\end{array}$ & $1.8(1.3$ to 2.3$)$ & $\begin{array}{l}\text { With } 10 \% \text { less risk of } \\
\text { unnecessary biopsies }\end{array}$ \\
\hline $\begin{array}{l}\text { Out-of- } \\
\text { pocket costs }\end{array}$ & 5.5 (3.9 to 7.1$)$ & $\begin{array}{l}\text { With } € 100 \text { lower out-of- } \\
\text { pocket costs }\end{array}$ \\
\hline \multicolumn{3}{|c|}{$\begin{array}{l}\text { Abbreviations: } \mathrm{Cl}=\text { confidence interval; } \mathrm{WTP}=\text { willingness to pay. } \mathrm{Cl}=95 \% \text { confidence } \\
\text { interval based on the Krinsky Robb method adjusted for class probabilities The average } \\
\text { values of the interactions are taken into account (i.e., costs }=€ 112.50 \text {; mortality } \\
\text { reduction }=27.5 \% \text {; unnecessary treatment }=37.5 \% \text {; unnecessary biopsy }=50 \% \text { ). }\end{array}$} \\
\hline
\end{tabular}

educational level. This same phenomenon was found for men who were willing to pay for PC screening and/or did not have anxiety/ depressed feelings. Men were willing to pay $€ 188$ per year (CI: $€ 141-€ 258)$ for each $10 \%$ reduction in their relative risk of PCrelated death with $10 \%$, or $€ 87$ per year (CI: $€ 48-€ 137$ ) to get PC screening every 2 years instead of 4 years. Men were willing to trade-off $2.0 \%$ (CI: $1.6 \%-2.4 \%$ ) or $1.8 \%$ (CI: $1.3 \%-2.3 \%)$ risk reduction of PC-related death to decrease their risk of unnecessary treatment or unnecessary biopsy with $10 \%$, respectively.

There are no previous DCEs investigating how characteristics of PC screening determine men's preferences for participation in PC screening. However, a study that investigated the influence of information on preferences among men aged 50-70 years for introducing PC screening in Denmark, found that regardless of information level a PC screening programme was valued highly (Pedersen et al, 2011). These results are in line with our findings, which show that in general men had a positive attitude towards PC screening. Our finding that men were prepared to give up life expectancy to avoid side-effects of medical intervention was also found by a DCE who focused on patients' preferences for the management of non-metastatic PC (Sculpher et al, 2004).

Although PC screening intervals may differ among countries, the most widely used screening interval is screening every 4 years (Schröder et al, 2009). Our study showed that men preferred a shorter screening interval over a longer screening interval. These results are in line with other studies. In a cancer screening context, a DCE showed that people aged $50-75$ years significantly preferred colorectal cancer screening intervals shorter than 10 years over a 10-year screening interval (van Dam et al, 2010). Preferring a shorter screening interval over a longer screening interval was also found in another DCE study (Wordsworth et al, 2006), where women preferred more frequent cervical cancer screening. Several studies have shown that reassurance may be a motivation for and/ or a result of undergoing cancer screening (Cantor et al, 2002; Whynes et al, 2007). This stresses the importance of adequate information provided to potential screeners.

Men included in our study population showed preference heterogeneity for PC screening aspects. Information about preference heterogeneity may help physicians to understand individuals' preferences for screening. Awareness of and explicit addressing differences in personal values regarding screening in general may have a positive effect on the process and outcomes of screening initiation in individual patients. For example, our results showed that men with lower educational levels had a higher probability to prefer PC screening than men with higher educational levels. The implications are that physicians (1) should be aware that patients may overestimate their benefit of PC screening due to numeracy problems, (2) can have a role to prevent unrealistic expectations from PC screening, and (3) are able to reach an optimal shared decision-making regarding PC screening. Additionally, information about preference heterogeneity may also be useful to inform policy decisions. Tailored PC screening programmes may result in a better informed decision-making for screening. Noteworthy, as physicians and patients may differ on the desirability for PC screening, which may hamper the process and outcome of shared decision-making, further research about determining and comparing physicians' and men's preferences for prostate screening is recommended.

The present study had several limitations. First, the response rate of $46 \%$ was higher than expected and similar to other DCE studies (Ratcliffe et al, 2002; Hundley and Ryan, 2004; Wordsworth et al, 2006; de Bekker-Grob et al, 2010b), but this response rate is still not optimal. We cannot exclude selection bias, although our respondents did not differ from non-respondents in age or marital status. Additionally, the proportions of different educational levels in our study sample were quite similar with the general population. Second, the inclusion of numbers and rates in our DCE might have caused problems with understanding the choice task. However, $93 \%$ of the respondents passed the rationality test that was included in the questionnaire, and $76 \%$ of the respondents did not find the DCE questions difficult. We hence believe that this has not influenced the results to a large extent. Finally, the current results could gain credibility if it were possible to compare the stated preferences of men with their actual behaviour in a PC screening programme.

In conclusion, men are willing to trade-off some risk reduction of PC-related death to be relieved of the burden of biopsies or to avoid unnecessary treatments. Men with lower educational levels have a higher probability to prefer PC screening than men with higher educational levels. Increasing knowledge on overdiagnosis and overtreatment, especially for men with lower educational levels, is hence warranted to prevent unrealistic expectations from PC screening.

\section{ACKNOWLEDGEMENTS}

Grant support for this study was from the Department of Public Health, Erasmus MC-University Medical Centre Rotterdam, The Netherlands.

\section{REFERENCES}

Andriole GL, Crawford ED, Grubb 3rd RL, Buys SS, Chia D, Church TR, Fouad MN, Gelmann EP, Kvale PA, Reding DJ, Weissfeld JL, Yokochi LA, O'Brien B, Clapp JD, Rathmell JM, Riley TL, Hayes RB, Kramer BS, Izmirlian G, Miller AB, Pinsky PF, Prorok PC, Gohagan JK, Berg CD (2009) Mortality results from a randomized prostate-cancer screening trial. N Engl J Med 360: 1310-1319.

Bech M, Kjaer T, Lauridsen J (2011) Does the number of choice sets matter? Results from a web survey applying a discrete choice experiment. Health Econ 20: 273-286.

Bishop AJ, Marteau TM, Armstrong D, Chitty LS, Longworth L, Buxton MJ, Berlin C (2004) Women and health care professionals' preferences for Down's Syndrome screening tests: a conjoint analysis study. BJOG 111: 775-779.

Cantor SB, Volk RJ, Cass AR, Gilani J, Spann SJ (2002) Psychological benefits of prostate cancer screening: the role of reassurance. Health Expect 5: 104-113. 
Daly A, Hess S, Train K (2012) Assuring finite moments for willingness to pay in random coefficient models. Transportation 39: 267-297.

de Bekker-Grob EW, Hofman R, Donkers B, van Ballegooijen M, Helmerhorst TJ, Raat H, Korfage IJ (2010a) Girls' preferences for HPV vaccination: a discrete choice experiment. Vaccine 28: 6692-6697.

de Bekker-Grob EW, Hol L, Donkers B, van Dam L, Habbema JD, van Leerdam ME, Kuipers EJ, Essink-Bot ML, Steyerberg EW (2010b) Labeled versus unlabeled discrete choice experiments in health economics: an application to colorectal cancer screening. Value Health 13: 315-323.

de Bekker-Grob EW, Ryan M, Gerard K (2012) Discrete choice experiments in health economics: a review of the literature. Health Econ 21: 145-172.

Draisma G, Boer R, Otto SJ, van der Cruijsen IW, Damhuis RA, Schroder FH, de Koning HJ (2003) Lead times and overdetection due to prostate-specific antigen screening: estimates from the European Randomized Study of Screening for Prostate Cancer. J Natl Cancer Inst 95: 868-878.

Hensher DA, Rose JM, Greene WH (2005) Applied Choice Analysis: A Primer. Cambridge University Press: Cambridge.

Herbild L, Bech M, Gyrd-Hansen D (2009) Estimating the Danish populations' preferences for pharmacogenetic testing using a discrete choice experiment. The case of treating depression. Value Health 12: 560-567.

Hol L, de Bekker-Grob EW, van Dam L, Donkers B, Kuipers EJ, Habbema JD, Steyerberg EW, van Leerdam ME, Essink-Bot ML (2010) Preferences for colorectal cancer screening strategies: a discrete choice experiment Br J Cancer 102: 972-980.

Hugosson J, Carlsson S, Aus G, Bergdahl S, Khatami A, Lodding P, Pihl CG, Stranne J, Holmberg E, Lilja H (2010) Mortality results from the Goteborg randomised population-based prostate-cancer screening trial. Lancet Oncol 11: 725-732.

Hundley V, Ryan M (2004) Are women's expectations and preferences for intrapartum care affected by the model of care on offer? BJOG 111: $550-560$.

Krinsky I, Robb AL (1986) On approximating the statistical properties of elasticities. Rev Econ Stat 68: 715-719.

Lancsar E, Louviere J (2008) Conducting discrete choice experiments to inform healthcare decision making: a user's guide. Pharmacoeconomics 26 : 661-677.

Mangham LJ, Hanson K, McPake B (2009) How to do (or not to do)... Designing a discrete choice experiment for application in a low-income country. Health Policy Plan 24: 151-158.

Pedersen LB, Gyrd-Hansen D, Kjaer T (2011) The influence of information and private versus public provision on preferences for screening for prostate cancer: a willingness-to-pay study. Health Policy 101: 277-289.

Phillips KA, Van Bebber S, Marshall D, Walsh J, Thabane L (2006) A review of studies examining stated preferences for cancer screening. Prev Chronic Dis 3: A75.

Ratcliffe J, Van Haselen R, Buxton M, Hardy K, Colehan J, Partridge M (2002) Assessing patients' preferences for characteristics associated with homeopathic and conventional treatment of asthma: a conjoint analysis study. Thorax 57: 503-508.

Roobol MJ, Kerkhof M, Schroder FH, Cuzick J, Sasieni P, Hakama M, Stenman UH, Ciatto S, Nelen V, Kwiatkowski M, Lujan M, Lilja H, Zappa M, Denis L, Recker F, Berenguer A, Ruutu M, Kujala P, Bangma CH, Aus G, Tammela TL, Villers A, Rebillard X, Moss SM, de Koning HJ, Hugosson J, Auvinen A (2009) Prostate cancer mortality reduction by prostate-specific antigen-based screening adjusted for nonattendance and contamination in the European Randomised Study of Screening for Prostate Cancer (ERSPC). Eur Urol 56: 584-591.

Ryan M (2004) Discrete choice experiments in health care. BMJ 328: $360-361$.

Ryan M, Gerard K (2003) Using discrete choice experiments to value health care programmes: current practice and future research reflections. Appl Health Econ Health Policy 2: 55-64.

Schroder FH, Hugosson J, Roobol MJ, Tammela TL, Ciatto S, Nelen V, Kwiatkowski M, Lujan M, Lilja H, Zappa M, Denis LJ, Recker F, Berenguer A, Maattanen L, Bangma CH, Aus G, Villers A, Rebillard X, van der Kwast T, Blijenberg BG, Moss SM, de Koning HJ, Auvinen A (2009) Screening and prostate-cancer mortality in a randomized European study. $\mathrm{N} \mathrm{Engl} J$ Med 360: 1320-1328.

Sculpher M, Bryan S, Fry P, de Winter P, Payne H, Emberton M (2004) Patients' preferences for the management of non-metastatic prostate cancer: discrete choice experiment. BMJ 328: 382.

Sennfalt K, Carlsson P, Varenhorst E (2006) Diffusion and economic consequences of health technologies in prostate cancer care in Sweden, 1991-2002. Eur Urol 49: 1028-1034.

Street DJ, Burgess L, Louviere JJ (2005) Constructing optimal and nearly optimal stated choice experiments. Intern J Res Marketing 22: 459-470.

Swait J (1994) A structural equation model of latent segmentation and product choice for cross sectional revealed preference choice data. J Retailing Consumer Serv 1: 77-89.

van Dam L, Hol L, de Bekker-Grob EW, Steyerberg EW, Kuipers EJ, Habbema JD, Essink-Bot ML, van Leerdam ME (2010) What determines individuals' preferences for colorectal cancer screening programmes? A discrete choice experiment. Eur J Cancer 46: 150-159.

Whynes DK, Philips Z, Avis M (2007) Why do women participate in the English cervical cancer screening programme? J Health Econ 26: 306-325.

Wordsworth S, Ryan M, Skatun D, Waugh N (2006) Women's preferences for cervical cancer screening: a study using a discrete choice experiment. Int J Technol Assess Health Care 22: 344-350.

This work is published under the standard license to publish agreement. After 12 months the work will become freely available and the license terms will switch to a Creative Commons AttributionNonCommercial-Share Alike 3.0 Unported License. 


\section{APPENDIX 1}

Example of a choice set

Thirty-five out of every 1000 men that will die is caused by PC. Which alternative do you prefer to reduce your risk to die from PC: no screening, screening programme 1, or screening programme 2? (please, tick one box)

\begin{tabular}{|c|c|c|c|}
\hline & NO SCREENING & PROGRAM 1 & PROGRAM 2 \\
\hline $\begin{array}{l}\text { Amount of men per } \\
1,000 \text { men that will die } \\
\text { from prostate cancer }\end{array}$ & $\begin{array}{l}35 \text { deaths } \\
\text { (0 deaths } \\
\text { prevented })\end{array}$ & 25 deaths & $\begin{array}{l}18 \text { deaths } \\
\text { (17 deaths } \\
\text { prevented) }\end{array}$ \\
\hline $\begin{array}{l}\text { Frequency of a blood } \\
\text { test }\end{array}$ & No blood test & $\begin{array}{l}\text { Every } 4 \text { year a } \\
\text { blood test }\end{array}$ & $\begin{array}{c}\text { Every } 3 \text { year a } \\
\text { blood test }\end{array}$ \\
\hline $\begin{array}{l}\text { Amount of men per } \\
1,000 \text { men with an } \\
\text { increased PSA that } \\
\text { receive an unnecess- } \\
\text { ary biopsy } \\
\text { (=no cancer detected, } \\
\text { although the blood test } \\
\text { suggested that a } \\
\text { biopsy was needed) }\end{array}$ & Not applicable & $\begin{array}{c}400 \text { unnecessary } \\
\text { biopsies } \\
\text { (600 correct } \\
\text { biopsies })\end{array}$ & $\begin{array}{c}800 \text { unnecessary } \\
\text { biopsies } \\
\begin{array}{c}\text { (200 correct } \\
\text { biopsies })\end{array}\end{array}$ \\
\hline $\begin{array}{l}\text { Amount of men per } \\
1,000 \text { treated men that } \\
\text { receive an unnecess- } \\
\text { ary treatment } \\
\text { (=no increase in life } \\
\text { expectancy, but there } \\
\text { is a risk of remaining } \\
\text { urine incontinence and } \\
\text { erection problems due } \\
\text { to treatment) }\end{array}$ & Not applicable & $\begin{array}{l}0 \text { unnecessary } \\
\text { treatments } \\
\text { (1.000 correct } \\
\text { treatments) }\end{array}$ & $\begin{array}{l}500 \text { unnecessary } \\
\text { treatments } \\
\text { (500 correct } \\
\text { treatments) }\end{array}$ \\
\hline $\begin{array}{l}\text { Out of pocket cost } \\
\text { per year during the } \\
\text { period of the screening } \\
\text { programme }\end{array}$ & $\begin{array}{l}0 \text { euro } \\
\text { per year }\end{array}$ & $\begin{array}{l}100 \text { euro } \\
\text { per year }\end{array}$ & $\begin{array}{l}50 \text { euro } \\
\text { per year }\end{array}$ \\
\hline $\begin{array}{l}\text { Which alternative } \\
\text { would you choose? }\end{array}$ & & & \\
\hline
\end{tabular}

\section{APPENDIX 2}

\section{Methodology}

Latent class model. The probability that respondent $n$ belongs to class segment $c$, is given by a class assignment model. The class assignment probability is

$$
P_{n c}=\frac{\exp \left(\theta_{c} q_{n c}\right)}{\sum_{c=1}^{C} \exp \left(\theta_{c^{\prime}} q_{n c^{\prime}}\right)}
$$

where $q_{n c}$ represents covariates (e.g., age, income), and $\theta_{c}$ represents parameters to be estimated. If no covariates are included in the class assignment model, then the model can be estimated with constants only. In such a case, all respondents will have the same probability of belonging to a given class or segment. When covariates are included in the class assignment model, the class membership probability will differ depending on the covariates included in the model. For model identification, the parameters (and/or constants) for one class are required to be set to zero, such that all the remaining parameters are interpreted as being relative to this class. Note that in estimating the model, the analyst must a priori determine the number of classes to be estimated.

Conditional on belonging to a given class $c$, the probability that individual $n$ chooses alternative $j$ in choice set $s$ is given as

$$
P_{n s j \mid c}=\frac{\exp \left(\beta_{k \mid c} x_{n s j k}\right)}{\sum_{i=1}^{J} \exp \left(\beta_{k \mid c} x_{n s i k}\right)}
$$

where $\beta_{k \mid c}$ represent class-specific parameter estimates to be estimated and $x_{n s j k}$ represent the attributes associated with the alternatives described within the DCE. 
Panel latent class model. Panel latent class model means that the model accounts for the pseudo panel nature of the DCE data as each respondent completed several choice tasks. In the DCE employed herein, each respondent completed 16 choice tasks. As such, the probability that a respondent is observed to make a particular sequence of choices over the 16 choice tasks, conditional on belonging to class $\mathrm{c}$ is given as

$$
P_{n \mid c}^{*}=\prod_{s=1}^{S=16}\left(\frac{\exp \left(\beta_{k \mid c} x_{n s j k}\right)}{\sum_{i=1}^{J} \exp \left(\beta_{k \mid c} x_{n s i k}\right)}\right)^{y_{n s j}},
$$

Given Equation (iii), we use maximum likelihood estimation to locate the parameters of interest, $\theta_{c}$ and $\beta_{k \mid c}$. We do this maximising the log-likelihood function of the model, which is given as

$$
\log L=\sum_{n=1}^{N} \ln \left(\sum_{c=1}^{C} P_{n c}\left(P_{n \mid c}^{*}\right)\right) .
$$

where $y_{n j s}$ is an indicated variable equal to one if alternative $j$ was observed to be chosen by respondent $n$ in choice set $s$, or zero otherwise.
By making use of the product of the probabilities (Equation (iii)) in the log-likelihood function (Equation (iv)), as opposed to the individual choice set probabilities (Equation (ii)), the model estimates the probability of observing sequence of choices made over the 16 choice tasks. As such, the model accounts for the pseudo panel nature of the DCE data.

Class assignment utility functions. In addition to the conditional utility functions, the final model allowed for several covariates to enter into the class assignment model (Equation (i)). The class assignment utility function for the final model is given as Equation (v).

$$
\begin{aligned}
V_{n c}= & \beta_{0 c}+\beta_{1 c} \text { higher education }{ }_{n}+\beta_{2 c} \text { depression }_{n} \\
& +\beta_{3 c} \text { wtp }(100 \text { euros })_{n}
\end{aligned}
$$

The parameter estimates of Equation (v) are obtained by maximising Equation (iv), given the data. 